\title{
Use of an omental pedicle graft to repair a large oesophageal defect
}

\author{
DAVID K KAPLAN, J ANDREW C THORPE \\ From Broadgreen Hospital, Liverpool, and the Northern General Hospital, Sheffield
}

The development of oesophagopleural fistula is a rare but life threatening complication of pulmonary resection. Successful outcome depends on appropriate and definitive action. We report a case in which an omental pedicle was delivered into the thorax to patch an oesophageal defect too large for direct suture.

\section{Case report}

A 41 year old man presented with a three month history of chest pain, decreased effort tolerance, and haemoptysis. A chest radiograph suggested a large cavitating neoplasm replacing the entire left upper lobe and diffuse opacification of the remaining lung on that side. Other investigations were non-contributory. Rigid bronchoscopy identified the presence of blood within the orifice of the left upper lobe bronchus but no endobronchial lesion was identified. At thoracotomy a large lung abscess was found to be replacing the entire left upper lobe. A considerable amount of the lower lobe was necrotic. Lobar dissection was impossible. The inflammatory reaction was so intense that intrapericardial division of the hilar structures was necessary to perform a pneumonectomy safely. There was no free pus within the thoracic cavity.

The patient's initial postoperative recovery was uneventful and he was discharged on the eighth day, well and having no medication. He presented 17 days later with back pain, vomiting, and abdominal distension. An emergency endoscopic examination showed a substantial full thickness defect of the oesophagus at $30 \mathrm{~cm}$. The patient was referred to the regional thoracic service, where an Omnipaque examination confirmed the presence of an oesophagopleural fistula.

Emergency thoracotomy was performed. A $5 \times 3 \mathrm{~cm}$ defect was identified in the oesophagus adjacent to the inferior pulmonary vein. The diaphragm was incised anteriorly at the junction of the tendonous and muscular areas, with a sufficiently long incision $(2.5 \mathrm{~cm})$ to deliver a long pedicle of omentum into the thorax. Subperiosteal excision of the seventh rib was performed to prepare an intercostal muscle pedicle flap. No attempt was made to approximate the edges of the oesophagus. The fistula was closed by creating a two layer patch with both pedicles (figure).

A central venous line was inserted to give total parenteral nutrition for six days. The patient recovered and was swallowing normally on discharge 31 days after the repair. A

Address for reprint requests: $\mathrm{Mr}$ David $\mathrm{K}$ Kaplan, Broadgreen Hospital, Liverpool L14 3LB.

Accepted 26 June 1987 barium examination performed before discharge showed normal appearances.

\section{Discussion}

Oesophagopleural fistula is a rare complication of pulmonary surgery. The reported incidence after pneumonectomy is $0.47 \%$.' It occurs even less frequently after other intrathoracic procedures. It has been suggested by some authors that the true incidence is higher. Most cases have occurred after pulmonary resection for inflammatory disease. The lesion invariably occurs in the middle third of the oesophagus and occurs nearly 10 times more frequently on the right than on the left. ${ }^{23}$

Fistulas that occur within three months of surgery are designated early, resulting either from direct trauma or from devascularisation of the oesophagus. Late fistulas are due to the presence of chronic infection (in the case of bronchopleural fistula) or to recurrence of malignant disease.

Several surgical approaches have been applied to this problem, with variable rates of success. ${ }^{1-7}$ Conservative

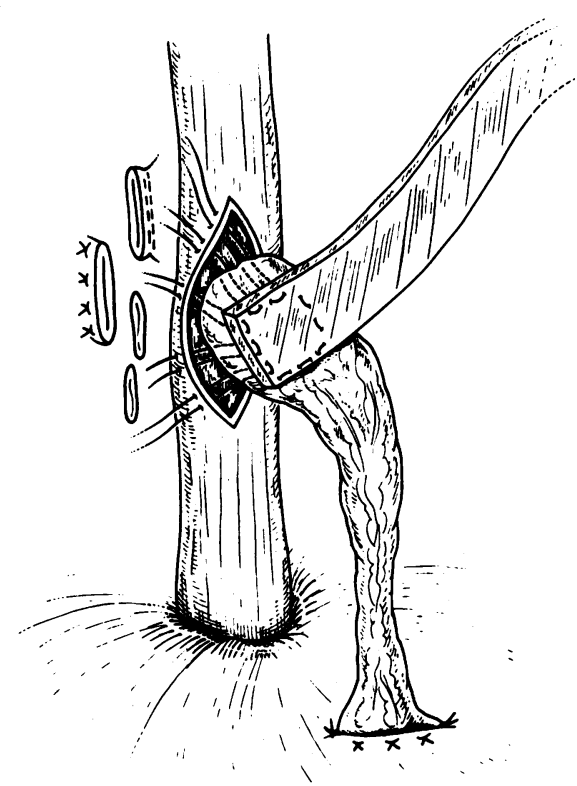

Diagram showing the technique used at operation: the pulmonary hilar structures have been divided and the omental and intercostal flaps, having been mobilised, are secured to the defect as a patch. 
measures such as gastrostomy, jejunostomy, or insertion of an intraluminal prosthesis are associated with an unacceptably high mortality. Closure of the defect is mandatory and must be accompanied by some form of adjunctive procedure. In one series five of eight simple closures broke down in the immediate postoperative period and needed further revision. ${ }^{2}$ The most reliable technique is reinforcement of the suture line with either a pleural or a pedicle intercostal muscle flap. This has a success rate of over $85 \% .^{23}$

In our case closure of the defect by direct suture with a simple reinforcing layer would have resulted in appreciable narrowing of the oesophagus and stricture would have assuredly followed cicatrisation. The omentum possesses a rich vascular network and has been used in various surgical circumstances both above and below the diaphragm. It is of undisputed value in promoting repair in areas of poor blood supply in the experimental and clinical setting and has been used successfully to repair bronchopleural fistulas ${ }^{8}$ and to protect intrathoracic oesophageal anastomoses. ${ }^{9}$ Delivery into the thorax is easy, with little in the way of attendant hazard. Consideration should be given to its use in any circumstances where, as in this case, ischaemic injury is a primary aetiological factor.

\section{References}

1 Takaro T, Walkup HE, Okano T. Esophagopleural fistula as a complication of thoracic surgery. $J$ Thorac Cardiovasc Surg 1960;40:179-93.

2 Sethi GK, Takaro T. Esophagopleural fistula following pulmonary resection. Ann Thorac Surg 1978;25:74-81..

3 Engleman RM, Spencer FC, Berg P. Postpneumonectomy i esophagopleural fistula. Successful one-stage repair. J Thorac Cardiovasc Surg 1970;59:871-6.

4 Dumont A, De Graef J. La fistule oesophagopleurale, complication tardive de la pneumonectomie. Lyon Chir 1961;57:481-8.

5 Richardson JD, Campbell D, Trinkle JK. Esophagopleural fistula after pneumonectomy. Chest 1976;69:795-7.

6 Shama D, Odell J. Esophagopleural fistula after pneumonectomy for inflammatory disease. J Thorac Cardiovasc Surg 1985;89: c 77-81.

7 Symes JM, Page AJF, Flavell G. Esophagopleural fistula. A late complication after pneumonectomy. J Thorac Cardiovasc Surg $\omega$ 1972;63:783-6.

8 Virkkula L. Eerola S. Use of omental pedicle for treatment of bronchial fistula after lower lobectomy. Scand $J$ Thorac Cardiovasc Surg 1975;9:287-90.

9 Goldsmith JS, Kiely AA, Randal HT. Protection of intrathoracic esophageal anastomoses by omentum. Surgery 1968;63:464-6. 